\title{
Reabsorption of sodium in the proximal renal tubule in cirrhosis of the liver
}

\author{
L. CHIANDUSSI, E. BARTOLI' ${ }^{1}$ AND S. ARRAS \\ From Istituto di Patologia Speciale Medica e Metologia Clinica dell'Università di Sassari, Sassari, Italy
}

SUMMARY Proximal tubular reabsorption was examined in patients with liver cirrhosis and ascites by a variety of indirect methods. Maximal diluting ability, urine flow rate, and free water clearance were reduced. During frusemide administration $\dot{V} /$ GFR was lower than in normal control subjects, indicating that proximal fractional reabsorption is enhanced in liver cirrhosis. This, by reducing $\mathrm{Na}$ delivery to the loop of Henle, impairs maximal urine osmolality. Mannitol, by reducing proximal reabsorption, restores availability of $\mathrm{Na}$ to the loop and urine concentrating ability during osmotic diuresis, whereas volume expansion with dextran was ineffective. This could be due to a persistent increase in renal vascular resistance preventing the rise in interstitial pressure responsible for driving fluid back into the proximal tubular lumen.

The clinical course of cirrhosis of the liver is punctuated by frequent episodes of $\mathrm{Na}$ retention with accumulation of ascites. Although hyperaldosteronism plays a prominent part in the formation of $\mathrm{Na}$ free urine (August et al., 1958), other factors must account for oedema formation in cirrhosis of the liver. Fluid retention despite diuretic therapy (Vesin, 1972), the appearance of refractory ascites (Eknoyan et al., 1970), rapid progression of sideeffects, and portal encephalopathy during forced diuresis (Sherlock et al., 1966) may also occur.

Earley and Martino (1970) proposed that $\mathrm{Na}$ reabsorption in the proximal tubule is enhanced in cirrhosis of the liver for any given value of Pupita filtration rate (Earley et al., 1966; glomerular et al., 1963b). These studies, performed with the technique of distal blockade (Earley et al., 1966; Bartoli et al., 1968c), strengthened previous suggestions, based upon indirect experiments, that there was reduced diluting ability (Papper and Saxon, 1959) and impaired renal concentration correctable by mannitol (Pupita et al., 1963b), which lowers proximal $\mathrm{Na}$ reabsorption (Gennari and Kassirer, 1974). In addition, the administration of aldosterone to normal subjects did not reproduce the features of cirrhosis of the liver, indicating that factors other than aldosterone were important (Pupita et al.,

\footnotetext{
${ }^{1}$ Address for correspondence: Dr Ettore Bartoli, Istituto di Patologia Speciale Medica e Metodologia Clinica, Viale San Pietro 12, Sassari, Italy.
}

1963a). The concept that proximal tubule reabsorption may be increased in cirrhosis of the liver is supported by haemodynamic measurements which demonstrate that renal vascular resistance is increased: the kidney has a lower rate of perfusion than in normal subjects (Greco et al., 1967); this increased vascular resistance is not affected by intra-arterial injection of powerful vasodilators (Lancestremere et al., 1962).

As increased renal vascular resistance may well enhance proximal $\mathrm{Na}$ reabsorption (Earley and Martino, 1970), renal pathophysiology in cirrhosis of the liver may be summarised as follows (Schedl and Bartter, 1960): delivery of fluid and $\mathrm{Na}$ out of the proximal tubule is decreased because of reduced proximal filtration rate and/or increased fractional reabsorption along the proximal tubule. Consequently, less $\mathrm{Na}$ is available to the loop of Henle, which will transport a smaller amount of solutes from lumen to medullary interstitium, thus impairing urine concentrating and diluting ability: the latter is partially counterbalanced by increased $\mathrm{Na}$ reabsorption by the distal tubule. While this summary is consistent with most of the data available in the literature, the cause of increased proximal tubule reabsorption is obscure. Transepithelial transport across the proximal tubule is thought to depend upon the volume of extracellular fluid, falling sharply when this is expanded (Bartoli and Earley, 1971). As extracellular fluid volume is certainly expanded in cirrhosis of the liver, it has been proposed that the 
volume sequestered as ascites cannot act as a stimulus controlling renal $\mathrm{Na}$ reabsorption, which would be dependent upon the status of extracellular fluid in sites other than the peritoneal space. However, estimates of this space do not indicate that it is consistently decreased in cirrhosis of the liver (Ruol et al., 1962). As Na reabsorption may depend upon renal haemodynamics, it has been suggested that a fall in cardiac output would result in an increased secretion rate of catecholamines (Braunwald et al., 1966) and stimulation of the reninangiotensin axis (Reid et al., 1972): the consequent renal vasoconstriction will then cause increased reabsorption of $\mathrm{Na}$ by the proximal tubule. However, cardiac output is often found to be raised in cirrhosis of the liver (Traverso et al., 1966). This is one of the reasons why the term effective cardiac output is used to refer to the amount of the cardiac output which perfuses peripheral tissues. The presence of arteriovenous fistulas in cirrhosis of the liver may contribute to a hyperkinetic state, increased venous return, and increased volume of blood pumped by the heart per unit time in the face of reduced peripheral tissue perfusion:(Vesin, 1972). Alternatively, the presence of massive ascites may interfere with venous return (Guazzi et al., 1975). Our studies are aimed at clarifying the data relating to renal pathophysiology and proximal tubule reabsorption in cirrhosis of the liver.

\section{Methods}

SUBJECTS STUDIED

Studies were carried out on 25 patients with biopsy proven cirrhosis of the liver and ascites. The results were compared with those obtained in 33 control subjects, studied in the same way. Maximal diluting capacity was studied in 20 patients using previously reported techniques (Bartoli et al., 1968a), and the results compared with those obtained in the control group. Five patients and five control subjects were studied during water deprivation, before and during mannitol infusion.

\section{Maximal diluting capacity}

Maximal diluting capacity was tested by administering $30 \mathrm{ml}$ distilled water per $\mathrm{kg}$ body weight and then infusing maintenance hypotonic fluids intravenously at a rate equal to peak urine flow rate while collecting two to four consecutive clearance periods. These were repeated 15 minutes after the injection of $\mathbf{4 0}$ mg frusemide intravenously to suppress $\mathrm{Na}$ reabsorption along the loop of Henle. Glomerular filtration rate was calculated by 10 minute creatinine clearance; $\mathrm{Na}, \mathrm{K}$, osmolality $(\mathrm{mOsm} / \mathrm{kg}$ ) were measured by standard methods in urine (U) and plasma $(\mathrm{P})$; urine flow rate $(\dot{\mathrm{V}})$, free water $\left(\mathrm{C}_{\mathrm{H}_{2} \mathrm{O}}\right)$, osmolar clearance $\left(\operatorname{Cosm}=\frac{U}{\mathbf{P}} \cdot \dot{\mathrm{V}}\right)$ and free water clearance $\left(\mathrm{CH}_{2} \mathrm{O}=\dot{\mathrm{V}}-\mathrm{Cosm}\right)$ were calculated and expressed in $\mathrm{ml} / \mathrm{min}$.

\section{Maximal concentrating capacity}

Maximal concentrating capacity was tested by water deprivation followed by mannitol as previously described (Pupita et al., 1963b) Calculations were as above except that free water $\left(\mathrm{C}_{\mathrm{H}_{2} \mathrm{O}}\right)$ was negative and indicated as $\mathrm{TC}_{\mathrm{H}_{2} \mathrm{O}}$. Lastly, three patients underwent a test of maximal diluting capacity. When the peak rate of urine flow had been reached and clearance periods collected as described above, plasma volume was acutely expanded by the rapid infusion of an isotonic solution containing $6 \mathrm{~g} \%$ of dextran (molecular weight 70000 Daltons) at a rate of $20 \mathrm{ml}$ per minute on top of hypotonic maintenance infusions. During the last 20 minutes of dextran infusion, when $750 \mathrm{ml}$ had already been injected, two clearance periods were repeated. Means and standard deviations were computed, linear regressions were calculated by least square methods, significance between slopes and intercepts were performed by covariance analysis, and between means by paired and unpaired $t$ tests (Snedecor and Cochran, 1972).

\section{Results}

The Table shows the diluting and concentrating capacity of the kidney in cirrhosis of the liver compared with control subjects. All measured variables are abnormal in cirrhosis of the liver: glomerular filtration rate is reduced, $\mathrm{C}_{\mathrm{H}_{2} \mathrm{O}}$ is significantly lower than normal $(7 \cdot 2 \pm 7 \cdot 1$ vs $13.0 \pm$ $3.7 \mathrm{ml} / \mathrm{min}, \mathrm{P}<0.01)$ despite lower solute excretion indicated by Cosm $(3.0 \pm 14$ vs $3.8 \pm 2 \cdot 4, \mathrm{P}>0.05)$ while minimal urine osmolality is increased and $\mathrm{Na}$ excretion significantly reduced (Table): these data indicate that fractional reabsorption of $\mathrm{Na}$ by the whole kidney is increased. This cannot be attributed to the distal tubule, where an increased amount of free water would be generated, while, in fact, measurements show a depression. However, if enhanced distal tubular reabsorption were coupled to back diffusion of a volume of free water per unit time higher than normal per $100 \mathrm{ml}$ of GFR, it would still be possible to reconcile increased distal reabsorption with reduced diluting ability. The alternative explanation is that proximal isotonic transfer represents a higher percentage of GFR, thereby reducing the amount of $\mathrm{Na}$ delivered to the diluting segments of the nephron. If the former 
Reabsorption of sodium in the proximal renal tubule in cirrhosis of the liver

Table Means and standard deviations from patients with liver cirrhosis and normal control subjects

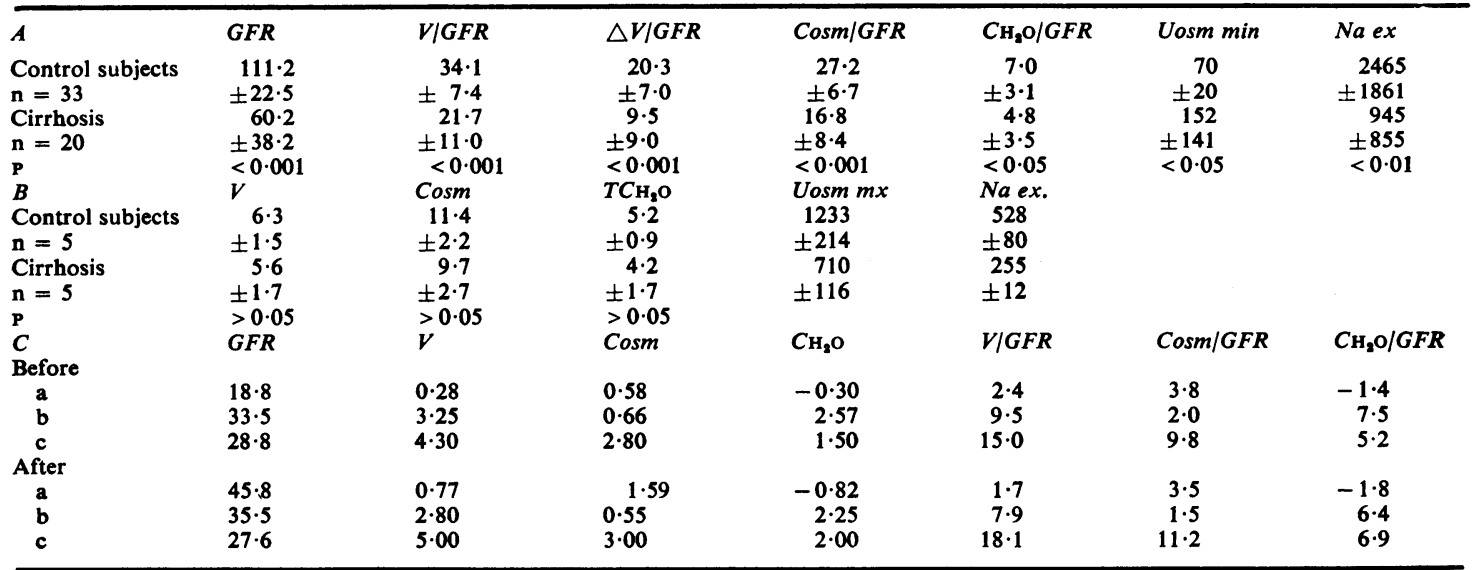

Part A: maximal diluting ability both before (Uosm) and after frusemide. Part B: water deprivation both before and during mannitol diuresis (before mannitol only Uosm is reported). Other variables refer to mannitol diuresis. Part C: three patients (a, b, c respectively) before (top) and immediately after (bottom) plasma volume expansion with dextran.

$\dot{\mathbf{V}}=$ baseline peak urine flow rate; $\mathbf{V F}=$ peak urine flow rate measured during frusemide; $\Delta \dot{\mathbf{V}}=\mathbf{V F}-\dot{\mathrm{V}} ; \mathbf{C o s m}=$ osmolar clearance; $\mathrm{TCH}_{2} \mathrm{O}=$ free water clearance; $\mathrm{GFR}=$ glomerular filtration rate; all these variables are in $\mathrm{ml} / \mathrm{min}$. Urine osmolality in $\mathrm{mOsm} / \mathrm{kg}=\mathrm{Uosm}$ minimal (min) or maximal $(\mathrm{mx}) ; \mathrm{Na}$ ex $=\mathrm{Na}$ excretion in $(\mathrm{mnol}) \mathrm{mEq} / \mathrm{min} ; \mathbf{n}=$ number of patients.

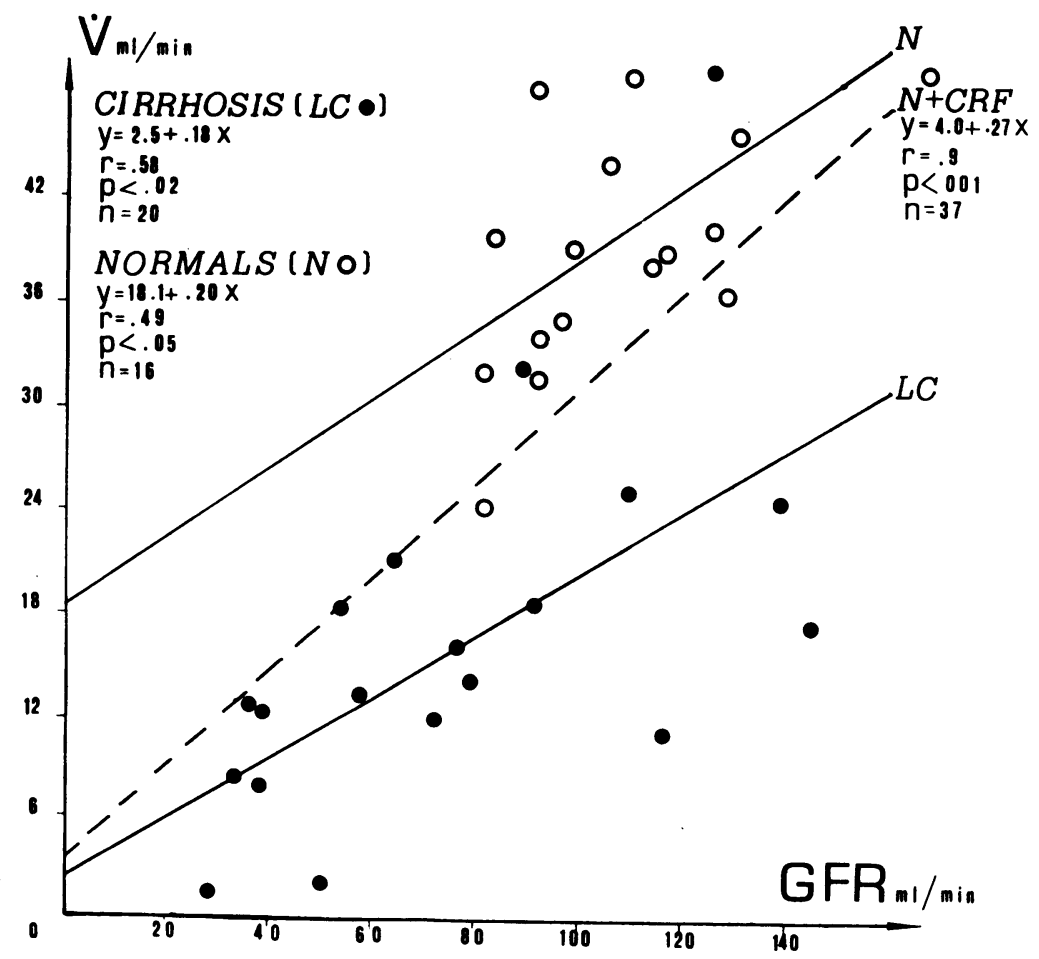

Fig. 1 In abscissa GFR ( $\mathrm{ml} / \mathrm{min})$, in ordinate urine flow rate $(\mathrm{ml} / \mathrm{min})$ measured during the action of frusemide superimposed on maximal water diuresis. Patients with cirrhosis - Normal subjects $\bigcirc$. The broken line indicates the regression equation calculated by combining $N C$ with patients with chronic renal failure $(C R F)$. 
possibility were correct, then the increment in urine flow measured during blockade of distal reabsorption obtained with frusemide should represent a larger fraction of glomerular filtration rate than in normal control subjects. Conversely, the latter interpretation would predict that urine flow as a fraction of GFR is reduced in cirrhosis of the liver; this volume is thought to represent fluid delivery out of the proximal tubule which would be diminished by enhancement of fractional reabsorption of filtrate across proximal epithelium. The Table, A, shows that both predictions are met, as $\dot{V} / G F R$, measured during administration of frusemide, is significantly lower in cirrhotic patients than in control subjects $(21 \cdot 7 \pm 11.0$ vs $34 \cdot 1 \pm 7 \cdot 4, \mathrm{P}<0.001) ; \triangle \dot{\mathrm{V}} / \mathrm{GFR}$ is also significantly lower $(9 \cdot 5 \pm 9 \cdot 0$ vs $20 \cdot 3 \pm 7 \cdot 0$, $P<0.001$ ).

In Fig. 1, peak urine flow rates measured during frusemide administration are plotted against the respective GFR values: the slope obtained in cirrhotic patients is not significantly different by covariance analysis from that obtained in control subjects $(F=0.95, P>0.05)$; however the intercept is clearly different $(F=22.2, P<0.01)$. The values obtained in control subjects do not cover the full range as they do in those with cirrhosis of the liver. To cover the whole range the data from healthy subjects were pooled with those obtained in patients with chronic renal failure, who have the same average fractional reabsorption after frusemide $(\dot{\mathrm{V}} / \mathrm{GFR}=34 \cdot 1 \pm 7 \cdot 4$ vs $40 \cdot 1 \pm 12 \cdot 3, \mathrm{P}>0.05)$ : the slope now obtained is different from that obtained in cirrhosis of the liver $(\mathrm{F}=8.65, \mathrm{P}<0.01)$.

The Table, $\mathbf{B}$, shows that while maximal urine osmolality is lower in cirrhosis of the liver, maximal $\mathrm{Na}$ transport by the loop of Henle, as estimated by negative free water clearance, is normal during mannitol diuresis. In these circumstances distal $\mathrm{Na}$ reabsorption is still high, resulting in reduced natriuresis in patients as compared with control subjects.

The Table, $\mathrm{C}$, and Fig. 2 show the data obtained in three patients where rapid expansion of plasma volume, achieved by dextran infusion, resulted in no detectable change in free water clearance and urine flow rate, while in one patient glomerular filtration rate rose following priming of his contracted vascular volume. In this patient there was no change in urine flow and $\mathrm{C}_{\mathrm{H}_{2} \mathrm{O}}$.
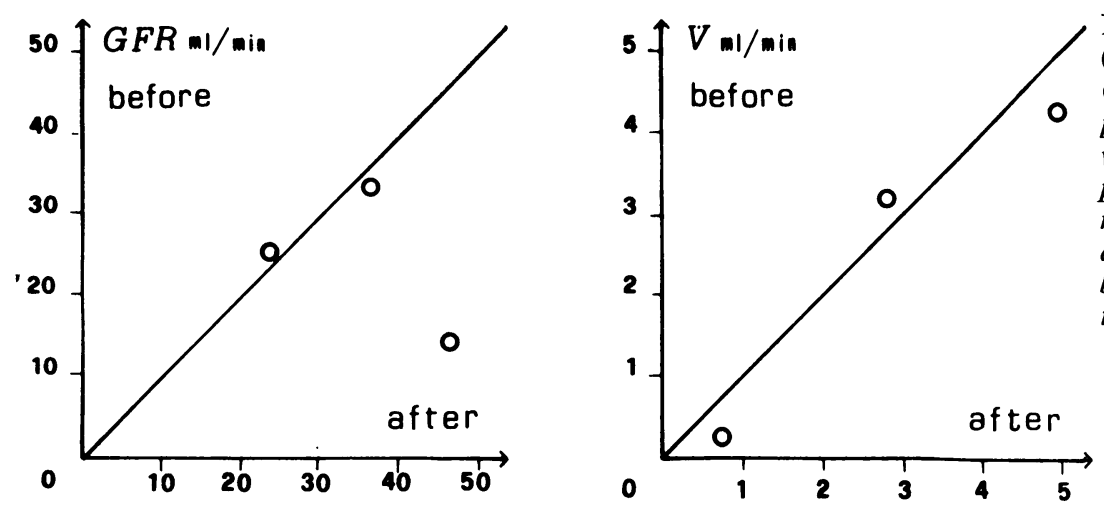

Fig. 2 GFR ( $\mathrm{ml} / \mathrm{min}), \dot{V}$ ( $\mathrm{ml} / \mathrm{min})$, Cosm $(\mathrm{ml} / \mathrm{min})$, and $\mathrm{CH}_{2} \mathrm{O}(\mathrm{ml} / \mathrm{min})$ in three patients duration maximal water diuresis (ordinate), plotted against the values measured on the same patients after acute volume expansion by dextran infusion, shown on the abscissa.
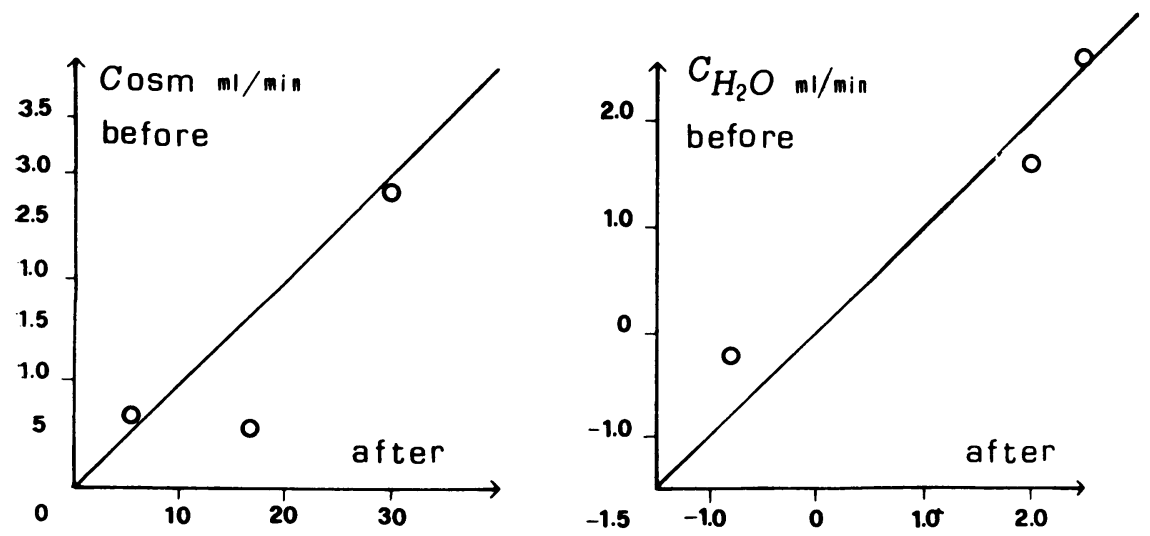
Discussion

Only a few methods are available for examining proximal $\mathrm{Na}$ reabsorption in humans in vivo. The most reliable is probably the technique of distal blockade with frusemide (Earley et al., 1966; Bartoli et al, 1968c), which inhibits chloride (and, therefore, $\mathrm{Na}$ and water) reabsorption along Henle's loop (Rocha and Kokko, 1974) and collecting ducts. When measured by this method, proximal rejection represents $34 \cdot 1 \pm 7 \cdot 4 \%$ of GFR in normal subjects, a figure significantly higher $(P<0.01)$ than that of $21 \cdot 7 \pm 11.0 \%$ of GFR in patients with cirrhosis of the liver and ascites. Figure 1 shows that there is a linear relationship over a wide range of GFR values between urine flow and filtration rates in cirrhosis of the liver. In normal subjects the slope is the same as in cirrhosis of the liver, but there is a significantly higher intercept. Unfortunately, low glomerular filtration rates cannot be measured in normal subjects.

By combining data obtained in patients with chronic renal failure, whose average fractional rejection of filtrate in the proximal tubue does not differ from normal, we can provide a full range of GFR values, from nearly zero to above 100 $\mathrm{ml} / \mathrm{min}$. The slope calculated from these pooled data indicates that $27 \%$ of filtered $\mathrm{Na}$ and water escape proximal reabsorption in normal subjects (Fig. 1, broken line), a figure significantly above that measured in cirrhosis of the liver, although compatible with direct measurements in experimental animals (Bartoli and Earley, 1971). Thus, both regression equations show that proximal reabsorption is enhanced in fractional terms in liver disease, although absolute reabsorption is lower, on average, because of the reduced rate of glomerular filtration.

This conclusion is supported by the impaired
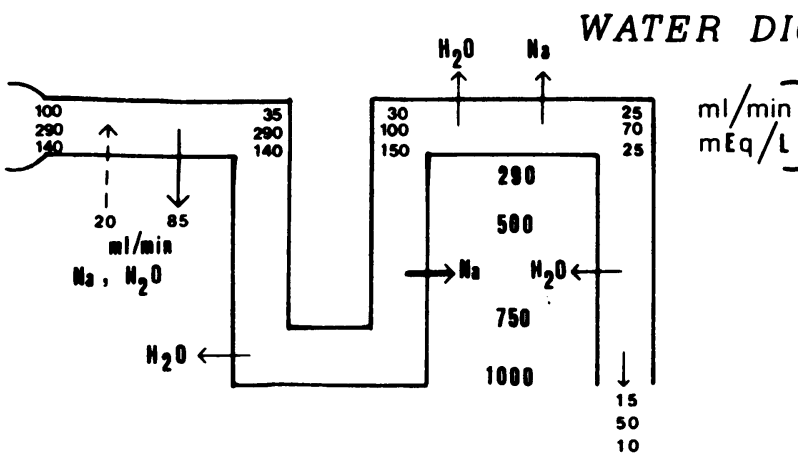

\section{DIURESIS}

NORMAL

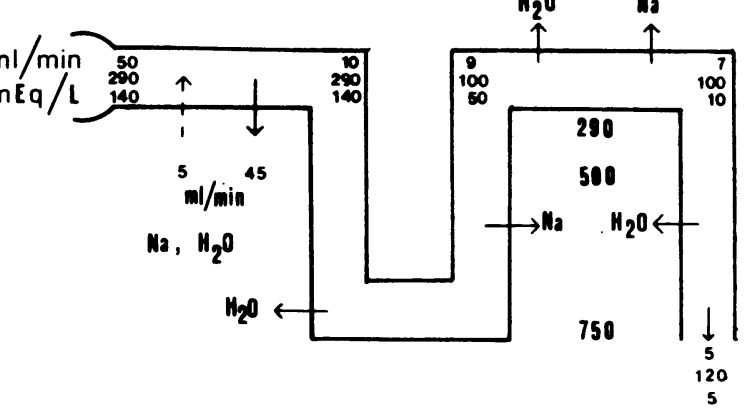

LIVER CIRRHOSIS

\section{MANNITOL DIURESIS}

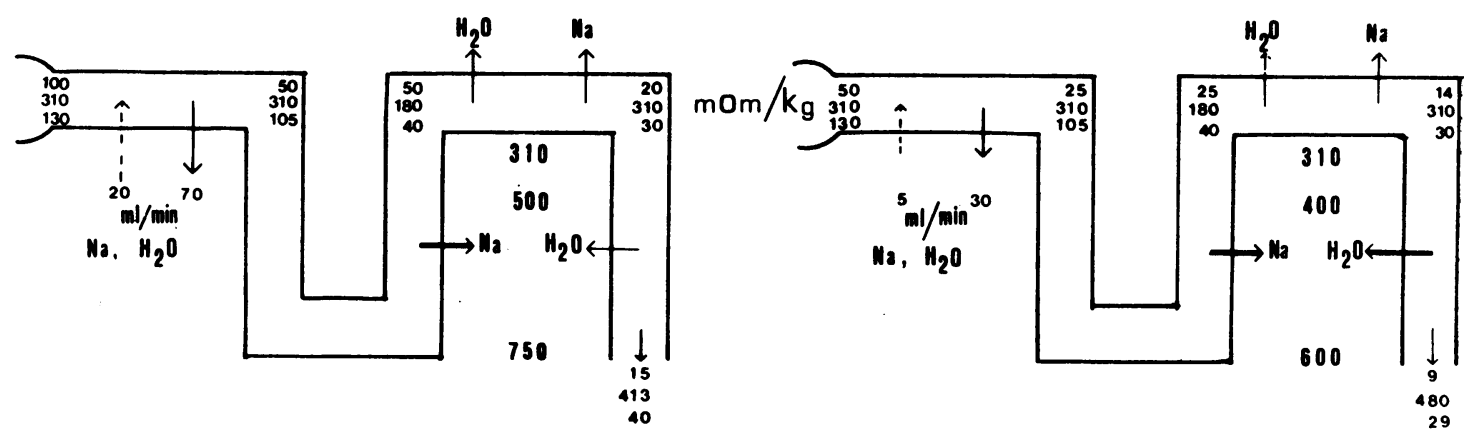

Fig. 3 Diagrammatic summary of results in control subjects and in liver cirrhosis during water or mannitol diuresis.

The values are taken from Table 1. The numbers within the lumen represent, from top to bottom, rate of filtration osmolality and sodium concentration. Passive back flux in the proximal tubule is indicated by the broken arrows. The interstitial osmolalities in the renal medulla are shown. The arrows have a thickness roughly proportional to sodium transport. 
concentrating ability, due to reduced delivery of $\mathrm{Na}$ to the loop of Henle. Alternatively, maximal Uosm may be low in cirrhotic patients because of high medullary blood flow (Zuin et al., 1976), and the consequent wash-out of interstitial solutes(Velasquez et al., 1973). Mannitol, by increasing medullary blood flow in normal subjects, could abolish the difference between them and cirrhotic patients. The table suggests that the reduced free water formation must be attributed to excessive fractional $\mathrm{Na}$ reabsorption in the proximal nephron. Figure 2 shows that expansion of plasma volume produced no change in free water and osmolar clearances, indicating that delivery from the proximal tubule had remained stable during dextran infusion

Apparently, while in two cases proximal rejection of filtrate did not change because GFR remained constant, one patient showed a striking increase in GFR which was not associated with any detectable variation in $\mathrm{Na}$ excretion and reabsorption. Such patients are refractory to manipulations of plasma volume, unlike normal subjects and experimental animals (Lambert et al., 1973). However, proximal reabsorption appears to be inhibited by mannitol in patients with cirrhosis presumably as a result of lowering of $\mathrm{Na}$ concentration within the tubular lumen to a minimum value below which $\mathrm{Na}$ transport cannot continue. Enhanced $\mathrm{Na}$ transport in the proximal tubule of patients with cirrhosis of the liver may then be mediated through the inhibition of passive back-flux into the tubular lumen that controls net transfer of fluid (Earley et al., 1972).

Proximal reabsorption is an active process, while back flow from capillary blood into the lumen through the tight junctions is due to Starling forces. In liver cirrhosis the increased renal vascular resistances may permit very low hydrostatic pressure within peritubular vessels: passive reflux of reabsorbate into the lumen will be depressed. This is born out by Figure 3, which shows two models of the nephron, one relating to normal conditions, and the other to patients with cirrhosis of the liver and ascites. In each situation renal function is depicted during water and mannitol diuresis. Reduced back flux into the lumen will increase proximal tubule reabsorption through purely passive pathways. As a consequence of this, delivery of tubular fluid to the loop of Henle will be depressed, imposing restrictions on the amount of $\mathrm{Na}$ transported into the medullary interstitium, with consequent reduction in maximal urine osmolality and free water generation. The increased delivery to the loop operated by mannitol results in adquate $\mathrm{Na}$ transport across the loop, with consequent normal abstraction of free water which may even represent an increased fraction of volume delivered in the absence of ADH as well in the presence of maximum $\mathrm{ADH}$.

\section{References}

August, J. T., Nelson, D. H., and Thorn, G. W. (1958). Response of normal subjects to large amounts of aldosterone. Journal of Clinical Investigation, 37, 1549-1555.

Bartoli, E. (1976). Fisiopatologia e clinica degli squilibri idroelettrolitici. La Medicina Internazionale, 23, 1-108.

Bartoli, E., and Earley, L. E. (1971). The relative contributions of reabsorptive rate and redisturbed nepthron filtration rate to changes in proximal tubular fractional reabsorption during acute saline infusion and aortic constriction in the rat. Journal of Clinical Investigation, 50, 2191-2203.

Bartoli, E., and Earley, L. E. (1972). Effects of saline infusion on glomerulotubular balance. Kidney International, 1 , 67-77.

Bartoli, E., Molaschi, M., Viara, A., and Milanese, U. (1968a). Studio sul potere di diluizione renale nella ipertensione arteriosa essenziale in fase precoce. Archivio Scienze Mediche, 125, 728-738.

Bartoli, E., Molaschi, M., Viara, A. and Milanese, U. (1968b). L'antidiuresi paradossa da saluretici nel diabete insipido. Rassegna di Fisiopatologia Clinica e Terapeutica, 40, 305-343.

Bartoli, E., Molaschi, M., Viara, A., Milanese, U., and Piazza, A. (1968c). Possibilita di studio della funzione renale nell'uomo mediante iniezione endovenosa di furosemide. Archivio per le Scienze Mediche, 125, 708-718.

Braunwald, E., Chidsey, C. A., Pool, P. E., Sonnenblick, E. H., Ross, J. Jr., Mason, D. T., Spann, J. F., and Covell, W. (1966). Congestive heart failure. Biochemical and physiological considerations. Annals of Internal Medicine, 64, 904-941.

Earley, L. E., Humphreys, M. H., and Bartoli, E. (1972). Capillary circulation as a regulator of sodium reabsorption and excretion. Circulation Research, 30/31, Suppl. 2, 1-18.

Earley, L. E., and Martino, J. A. (1970). Influence of sodium balance on the ability of diuretics to inhibit tubular reabsorption. Circulation, 42, 323-334.

Earley, L. E., Martino, J. A., and Friedler, R. M. (1966). Factors affecting sodium reabsorption by the proximal tubule as determined during blockade of distal sodium reabsorption. Journal of Clinical Investigation, 45, 16681684.

Eknoyan, G., Martinez-Maldonado, M., Yium, J. J., and Suki, W. N. (1970). Combined ascitic-fluid and furosemide infusion in the management of ascites. New England Journal of Medicine, 282, 713-717.

Gennari, G. F., and Kassirer, J. P. (1974). Osmotic diuresis. New England Journal of Medicine, 291, 714-720.

Greco, F., Chiandussi, L., Bert, G., Ruschena, A., Sardi, G., Vaccarino, A., A.gostoni, A., and Zardini, P. (1967). L'emodinamica sistemica e renale in cirrotici compensati e scompensati. Minerva Medica, 58, 370-374.

Guazzi, M., Polese, A., Magrini, F., Fiorentini, C., and Olivari, M. T. (1975). Negative influences of ascites on the cardiac function of cirrhotic patient. American Journal of Medicine, 59, 165-170.

Lambert, M., Bartoli, E., and Earley, L. E. (1973). Effect of plasma loading on rat proximal tubule reabsorption. (Abstract.) Clinical Research, 21, 695.

Lancestremere, R. G., Davidson, P. L., Earley, L. E., O'Brien, F. J., and Papper, S. (1962). Renal failure in Laennec's cirrhosis. II. Simultaneous determination of cardiac output and renal hemodynamics. Journal of Clinical Investigation, 42, 1922-1927.

Martino, J. A., and Earley, L. E. (1967). Demonstration of a 
role of physical factors as determinants of the natriuretic response to volume expansion. Journal of Clinical Investigation, 46, 1963-1978.

Papper, S., and Saxon, L. (1959). The diuretic response to administered water in patients with liver disease. II. Laennec's cirrhosis of the liver. Archives of Internal Medicine, 103, 750-757.

Pupita, F., Bartoli, E., and Molaschi, M. (1963a). Studi sulle modificazioni indotte dalla somministrazione di aldosterone sulla funzione tubulare renale (prossimale e distale). Gazzetta Internatzionale di Medicina e Chirurgia, 68 (Dec. Supplement), 3295-3304.

Pupita, F., Bartoli, E., Molaschi, M., Sismondi, P., and Sartorius, S. (1963b). Studio della funzione tubulare renale (prossimale e distale) negli stati edemigeni. Gazzetta Internatzionale di Medicina e Chirurgia, 68 (Dec. Supplement), 3135-3152.

Reid, I. A., Schrier, R. W., and Earley, L. E. (1972). An effect of extrarenal beta adrenergic stimulation on the release of renin. Journal of Clinical Investigation, 51, 1861-1869.

Rocha, A. S., and Kokko, J. P. (1973). Sodium chloride and water transport in the medullary thick ascending limb of Henle. Journal of Clinical Investigation, 52, 612-623.

Ruol, A., Menozzi, L., and Furlanello, F. (1962). Modalità di distribuzione e di diffusione dell'acqua corporea nella cirrosi epatica. Minerva Gastroenterologica, 8, 37-42.

Schedl, H. P., and Bartter, F. C. (1960). An explanation for and experimental correction of the abnormal water diuresis in cirrhosis. Journal of Clinical Investigation, 38,
248-261.

Sherlock, S., Senewiratne, B., Scott, A., and Walker, J. G. (1966). Complications of diuretic therapy in hepatic cirrhosis. Lancet, 1, 1049-1053.

Snedecor, G. W., and Cochran, W. G. (1972). Statistical Methods. Iowa State University Press: Ames, Iowa, USA.

Traverso, H. D., Raynaud, C., Blanchon, P., Roberti, A., Vesin, P., Viguié, R., and Kellershohn, C. (1966). Etude des clearances de l'inuline et du PAH, du débit cardiaque, du $\mathrm{Na}$ et du $\mathrm{K}$ échangeables et des liquides extracellulaires, au cours de l'évolution de la cirrhose du foie. Revue Internationale d'Hepatologie, 16, 1377-1398.

Velasquez, M. T., Notargiacomo, A. V., and Cohn, J. N. (1973). Comparative effects of saline and mannitol on renal cortical blood flow and volume in the dog. American Journal of Physiology, 224, 322-327.

Vesin, P. (1972). Water, electrolyte and acid-base disorders in liver disease. In Clinical Disorders of Fluid and Electrolyte Metabolism. Edited by M. H. Maxwell and C. R. Kleeman, 2nd edition. McGraw-Hill: New York.

Vesin, P., Blanpin, O., Julien, C., Giboudeau, J., Renault, H., and Cattan R. (1959). Traitement des oèdemes réfractaires par les spirolactones (anti-aldostérone): étude clinique et biologique. Bulletin de la Societé Medicale des Hopitaux (Paris), 75, 826-840.

Zuin, R., Gatta, A., Prandoni, P., Finocchio G. F., Merkel, C., and Ruol, A. (1976). Measurement of the renal blood flow in cirrhotic patients with the ${ }^{133}$ Xenon wash-out technique. Kidney International (abstract), 9, 534. 